\title{
BMJ Open Randomised controlled study comparing general and spinal anaesthesia with and without a tourniquet on the outcomes of total knee arthroplasty: study protocol
}

\author{
Mikko Tuomas Rantasalo, ${ }^{1}$ Riku Palanne, ${ }^{2}$ Katarina Juutilainen, ${ }^{2}$ \\ Pekka Kairaluoma, ${ }^{2}$ Rita Linko, ${ }^{2}$ Elina Reponen, ${ }^{2}$ Teemu Helkamaa, ${ }^{1}$ Anne Vakkuri, ${ }^{2}$ \\ Klaus T Olkkola, ${ }^{3}$ Rami Madanat, ${ }^{1}$ Noora Kati Annukka Skants ${ }^{2}$
}

To cite: Rantasalo MT,

Palanne R, Juutilainen $\mathrm{K}$, et al. Randomised controlled study comparing general and spinal anaesthesia with and without a tourniquet on the outcomes of total knee arthroplasty: study protocol. BMJ Open 2018;8:e025546. doi:10.1136/ bmjopen-2018-025546

- Prepublication history for this paper is available online. To view these files, please visit the journal online (http://dx.doi. org/10.1136/bmjopen-2018025546).

Received 20 July 2018 Revised 12 September 2018 Accepted 7 November 2018

Check for updates

(C) Author(s) (or their employer(s)) 2018. Re-use permitted under CC BY-NC. No commercial re-use. See rights and permissions. Published by BMJ.

For numbered affiliations see end of article.

Correspondence to Dr Mikko Tuomas Rantasalo; mikko.rantasalo@hus.fi

\section{ABSTRACT}

Introduction Total knee arthroplasty is a highly effective treatment for end-stage knee osteoarthritis, and it is usually performed under spinal or general anaesthesia with or without a surgical tourniquet. Some debate about the preferred mode of anaesthesia regarding patient outcomes remains. The aim of this study, which compares general and spinal anaesthesia with and without a tourniquet on the outcomes of total knee arthroplasty, is to determine the optimal type of anaesthesia regimen and assess the effect of a tourniquet on the patient's recovery following total knee arthroplasty.

Methods and analysis This study is a randomised, controlled, parallel-group, four-arm study comparing spinal and general anaesthesia with and without a tourniquet in 400 patients undergoing fast-track total knee arthroplasty, with a 12-month follow-up. The primary outcome is cumulative intravenous oxycodone consumption by patient-controlled analgesia during the first 24 postoperative hours. Secondary outcomes include postoperative nausea and vomiting, the length of hospital stay, the duration of the surgery, blood loss, demand for surgical unit resources, complications, readmissions, postoperative knee function, range of motion, healthrelated quality of life, prolonged pain and mortality.

Ethics and dissemination This study's protocol is in accordance with the declaration of Helsinki. The results of this study will be disseminated in international peerreviewed journals.

Trial registration number NCT03364088; Pre-results.

\section{INTRODUCTION}

\section{Background and rationale}

Total knee arthroplasty (TKA) is a common and highly effective orthopaedic procedure for treating end-stage knee osteoarthritis with good long-term results when conservative treatment provides inadequate relief. ${ }^{1}$ Over the last few decades, the number of TKA procedures has increased remarkably

\section{Strengths and limitations of this study}

- The large number of patients and methodological rigour of this study will decrease the risk of biases and improve the power of the results.

- Exclusion criteria are clinically relevant and, consequently, the results of this study can be used in clinical practice with certain limitations.

- The study is conducted in a high-volume tertiary arthroplasty centre, which has well-established standardised fast-track protocols for total knee arthroplasty, providing consistency in interventions and assessments.

- All the hospital's experienced surgeons and anaesthetists are involved in the study and total knee arthroplasty is performed using a single arthroplasty system (Triathlon Total Knee System); therefore, the results of this study are not physician or implant dependent.

- Blinding the anaesthesia method or tourniquet use from personnel or patients is not possible and patients may communicate with each other postoperatively, which may affect self-reported data; this is, therefore, a limitation of the study.

in both North America and Europe, and some estimates also project a fast-growing incidence of TKA in the future. ${ }^{23}$ Modern fast-track TKA protocols reduce length of stay (LOS) and expedite the ambulation and general rehabilitation without increasing complications. ${ }^{4-8}$ Nevertheless, the acute and chronic postoperative pain following TKA and its impact on patient recovery and rehabilitation, LOS and long-term results remains a problem. Because of prolonged pain, $10 \%-36 \%$ of patients are dissatisfied after TKA. ${ }^{9-12}$ Furthermore, growing concerns about chronic opioid use and the opioid epidemic have emphasised the need 
for well-designed studies that assess how to enhance postoperative pain management. ${ }^{13}$ In a recent study, postoperative pain led to unplanned 90-day readmission in $14 \%$ of cases. ${ }^{14}$ Pain after TKA is also a major cause for revision surgery. In a study identifying reasons for revision surgery after TKA, Sadoghi et $a l^{15}$ discovered pain was the third most common independent factor after aseptic and septic loosening of the implant.

TKA is usually performed under spinal anaesthesia (SA) or general anaesthesia (GA) with or without a tourniquet. Previous retrospective database studies comparing TKA performed under SA and GA show that patients receiving SA benefit regarding morbidity, mortality, complications, need for intensive care treatment, need for blood transfusions and LOS. ${ }^{16-20}$ However, SA may be associated with serious complications such as spinal haematoma, which occurs in approximately 1 in 22000-480000 patients. $^{21}$ Generally, anaesthetic complications are rare in surgical operations and there are only small differences between SA and GA regarding, for example, mortality $(0.1 \%-$ $0.18 \%)$ and pneumonia $(0.69 \%-0.94 \%) .{ }^{18}$ In a recent systematic review, both SA and GA were found to be equally effective without increased morbidity. ${ }^{22}$ Currently, both regimens are widely accepted and considered safe anaesthesia methods. To our knowledge, only one prospective randomised study has been published comparing SA and GA on postoperative rehabilitation and outcomes in patients undergoing fast-track TKA. ${ }^{23}$ The study, which assessed 120 patients, reported less acute pain and less nausea and dizziness in the GA group compared with the SA group.

The use of a tourniquet can also affect the outcome of TKA. A tourniquet may reduce operative time and blood loss, but may weaken the thigh muscles and increase postoperative pain, thus hindering mobilisation and increasing LOS. $^{24-26}$ An unexpected increase in total blood loss has also been described when using a tourniquet in TKA. ${ }^{27}$ Several studies have reported similar outcomes with both techniques regarding postoperative blood loss measured using drains, blood transfusion rates, operative time, component positioning, cement fixation, LOS and knee function after 3 months. 252829

The anaesthesia method used in TKA is usually based on hospital protocols, patients' comorbidity, the experience and preference of the anaesthetist, ${ }^{30}$ and patient preference. The growing demand for TKA will challenge us to find medically and economically optimal solutions for performing these procedures with good long-term clinical outcomes. These solutions may improve the cost-effectiveness of TKA. Because of the limitations of registry data and the paucity of randomised controlled studies and evidence comparing the outcomes of TKA under GA and SA, more high-quality studies are needed. This large-scale 400-patient randomised study allows us to compare modern anaesthesia regimens and tourniquet use in a fast-track protocol regarding both the short-term and long-term outcomes of patients undergoing TKA. To our knowledge, this is the first randomised controlled study comparing SA and GA with and without a surgical tourniquet in a four-arm set-up.

\section{Objectives}

\section{Primary objective}

The primary objective of our study is to determine the optimal type of anaesthesia and the impact of using a surgical tourniquet in TKA regarding acute postoperative pain, postoperative nausea and vomiting (PONV), and LOS. The hypothesis is that outcomes are equal between all four study groups (GA with a tourniquet, GA without a tourniquet, $\mathrm{SA}$ with a tourniquet and $\mathrm{SA}$ without a tourniquet).

\section{Secondary objectives}

- To compare the following between the GA and SA groups, 3 and 12 months postoperatively: postoperative knee function measured using the Oxford Knee Score (OKS) ${ }^{31-34}$ and range of motion (ROM); complications; readmissions; health-related quality of life, as assessed using the $15 \mathrm{D}$ questionnaire ${ }^{35-38}$; and the incidence of postoperative prolonged pain $(\geq 3$ months) and chronic pain ( $\geq 12$ months), as assessed using the Brief Pain Inventory short form (BPI-sf). ${ }^{39}$

- To compare the following between the tourniquet and non-tourniquet groups, 3 and 12 months postoperatively: operation time; blood loss; complications; readmissions; postoperative knee function, as assessed using the OKS and ROM; health-related quality of life, as assessed using the $15 \mathrm{D}$ questionnaire; and the incidence of postoperative prolonged pain ( $\geq 3$ months) and chronic pain ( $\geq 12$ months), as assessed using the BPI-sf.

- To determine whether patient body composition, as measured by bioelectrical impedance analysis, ${ }^{40-42}$ correlates with the following after TKA: LOS; complications; mortality; readmissions; need for intensive care; surgical outcome (OKS, ROM); quality of life (15D questionnaire); acute and prolonged pain (BPI-sf).

- To compare operating room (OR) and post-anaesthesia care unit (PACU) patient flow, monitoring and treatment demands (need for continuous arterial blood pressure monitoring, ventilation support or urinary catheter) between the GA and SA groups.

- To determine whether the preoperative Althaus risk index ${ }^{43}$ identifies patients at risk of prolonged $(\geq 3$ months) or chronic ( $\geq 12$ months) postoperative pain.

\section{METHODS AND ANALYSIS \\ Trial design}

The study is a randomised, controlled, parallel group, four-arm trial with a 12-month follow-up involving 400 patients undergoing TKA. The study compares SA and GA, with and without a tourniquet, in terms of acute and chronic postoperative pain, postoperative nausea, LOS, demand for surgical unit resources, knee function, health-related quality of life, complications, readmissions 


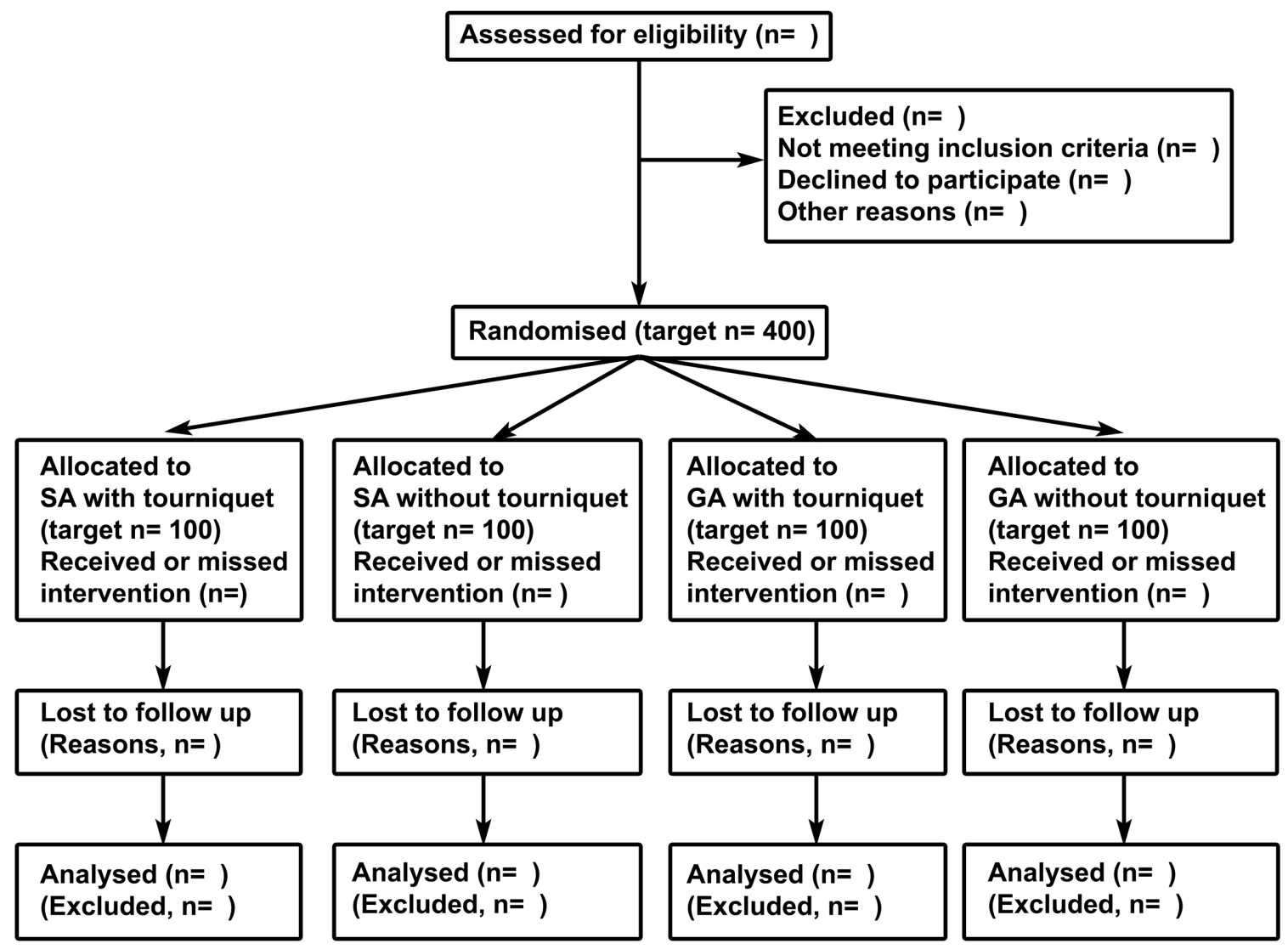

Figure 1 CONSORT flow diagram. GA, general anaesthesia; SA, spinal anaesthesia.

and mortality. Randomisation into four groups will be performed with a 1:1:1:1 allocation in 20 patient clusters.

\section{Study setting}

The study is performed in a single high-volume tertiary centre in Helsinki University Hospital. Peijas Hospital Arthroplasty Centre is a government-funded university hospital and part of the Finnish public healthcare system. All anaesthetists participated and all the participating joint arthroplasty surgeons have previously performed a minimum of 100 TKA procedures using the Triathlon knee system.

The study protocol construction follows the SPIRIT $2013^{44}$ and the CONSORT Statements ${ }^{45}$ (see figure 1) and has been published in the European Clinical Trials Database (EudraCT) of the European Medicines Agency (2016-002035-15), as well as on ClinicalTrials.gov (NCT03364088).

\section{Patient and public involvement}

Patients or public were not involved in the development, planning, recruitment, conduction or burden assessment of this study. After completion of the study, an information letter about the results will be provided for study participants.

\section{Patient enrolment and eligibility criteria}

The patients come to the Peijas Hospital outpatient clinic according to the usual hospital referral system.
The decision to perform TKA is made by the surgeon according to good clinical practice prior to and independently of study enrolment. Patient enrolment in this study will occur during the preoperative outpatient visit, usually 5-14 days prior to surgery. A total of 400 consecutive eligible patients will be enrolled in this trial.

All the following eligibility criteria must be met for the patient to be included in the study:

- Patients must be aged between 18 and 75 .

- Patients must have Kellgren-Lawrence ${ }^{46}$ grade 3 or 4 knee osteoarthritis resistant to conservative treatment (medication, physiotherapy, weight control). Other reasons for knee pain are excluded (differential diagnostics of lower back or hip problems). The knee osteoarthritis can be primary or secondary due to rheumatoid arthritis or other inflammatory joint disease.

- Patients must have had no prior major surgery to the same knee. Patients with a history of partial meniscectomy or knee joint debridement may be included.

- Patients must not have severe varus or valgus malalignment ( $>15$ degrees) or severe extension and flexion deficits (flexion contracture $>20$ degrees or maximum flexion $<90$ degrees).

- Body mass index (BMI) must be $\leq 40 \mathrm{~kg} / \mathrm{m}^{2}$.

- Patients must be class I-III in the American Society of Anesthesiologists (ASA) Presurgical Physical Status Classification System. ${ }^{47}$ 
- There must be no contraindication to the anaesthesia methods used in the trial.

- Patients must not have a history or very high risk of thromboembolic complications and demand for high-dose antithrombotic treatment during surgery.

- There must be no absolute contraindication to the medication used in the trial (eg, allergies to the medication), no moderate or severe renal insufficiency (glomerular filtration rate $<60 \mathrm{~mL} / \mathrm{min} / 1.73 \mathrm{~m}^{2}$ according to the Chronic Kidney Disease Epidemiology Collaboration calculation) and no illness influencing hepatic function.

- Patients must have no prior long-term use of opioids. Codeine, tramadol or buprenorphine are, however, allowed.

- Patients must not be under guardianship, pregnant, mentally or cognitively disabled, prisoners or doing military service.

- A signed and dated informed consent form is required before study enrolment. The patient must be capable of understanding the study information written in Finnish or Swedish (the official languages of Finland).

\section{Randomisation and blinding}

The randomisation envelopes, including the randomisation allocation forms to GA or SA and tourniquet or non-tourniquet groups, are created in 20-envelope sets. The 20-envelope sets are used to ensure that all four study arms are parallel, as well as to obtain evenly sized study groups should the study be prematurely terminated. Randomisation allocation forms are sealed in non-transparent envelopes by a person not involved in the study. The envelopes are kept in a locked cabinet at the surgical unit. Single envelopes are opened and thus individual patients are randomised by the anaesthesia nurse no earlier than 2 hours prior to the surgery. The anaesthesia and preparation for surgery are performed in accordance with the allocation form.

Blinding is neither feasible for the involved physicians and other medical staff nor for the patients, as it is obvious whether the patient is awake during the surgery or able to move his/her legs after surgery. Statistical data analysis is performed by an independent biostatistician.

\section{Assessments}

\section{Preoperative phase}

Medical data and history, including height, weight, allergies, tobacco use, alcohol use, ASA presurgical physical status class, previous illnesses and surgeries, and medication, together with preoperative standard laboratory tests, will be collected from every subject. Standard anteroposterior, sagittal and mechanical axis X-ray views will be taken to assess the degree of osteoarthritis, the anatomical and mechanical axis, and the malalignment of the subject's knee. Assessments are made using the OKS, the BPI-sf and the 15D questionnaire. ROM is measured by a physiotherapist. Body composition is estimated using bioelectrical impedance analysis (Omron BF-500; Omron,
Kyoto, Japan) if possible. With the available equipment, bioelectrical impedance can only be measured in patients weighing less than $150 \mathrm{~kg}$ and without prior metallic implants. The anaesthetist will fill out the applicable parts (questions 1-4) of the Althaus risk analysis for prolonged pain. ${ }^{43}$ The patients are then asked whether they prefer a combination of paracetamol/codeine or tramadol as their preferred pain medication. If neither medicine is suitable, the subject is excluded. Participants are familiarised with a patient-controlled analgesia (PCA) pump (CADD Legacy PCA Pump; Smiths Medical, Kent, UK) and with the numerical rating scale (NRS) for pain ${ }^{48}$ and nausea.

\section{Postoperative phase}

After the operation, patients will be mobilised as soon as possible either on the day of the surgery or, at the latest, on the first postoperative day according to fast-track protocol. The PCA pump is used during the first 24 postoperative hours. After 24 hours, the number of administered and attempted PCA oxycodone doses are registered. Using the NRS, pain is measured at rest, with the knee straight and with the hip flexed 45 degrees; with the knee flexed 45 degrees; and after walking $5 \mathrm{~m} .{ }^{23}{ }^{50}$ Following this, Althaus risk analysis is completed concerning acute pain (NRS pain in motion $\geq 5$ ) ${ }^{43}$ Pain medication, any additional anaesthesia for pain, medication for nausea, the NRS for nausea and the number of vomits are all registered. Any consultations, complications and need for intensive care, together with the corresponding reasons, are also documented, as is the time of hospital discharge or the time when the patient met the following hospital discharge criteria:

- Pain is controlled by regular pain medication.

- Patient can urinate.

- Ambulation is safe.

- Surgical wound secretion is minor.

- Medication use is understood by the patient.

- Home conditions and further care are arranged.

- Home care instructions and prescriptions are understood by the patient.

Post-hospital phase

Patients will be invited to the outpatient clinic 3 and 12 months after the operation. At that time, the OKS, BPI-sf and 15D questionnaires will be completed. ROM will be measured by a physician during both visits (see study timeline, table 1). Complications and mortality are verified using electronic medical records and the population register centre.

Interventions: anaesthesia, surgery and perioperative care Anaesthesia protocols and perioperative care for all groups

Patients will fast a minimum of 6 hours prior to surgery. Small amounts of clear liquids or Nutricia Preop drink (Nutricia Medical, Turku, Finland) are allowed 2 hours before operation. 


\begin{tabular}{|c|c|c|c|c|c|c|}
\hline Outpatient clinic & Preoperative clinic & Intervention & 24 hours & Discharge & 3 months & 12 months \\
\hline - & & & & & & \\
\hline & $\bullet$ & & & & & \\
\hline$\bullet$ & $\bullet$ & & & & & \\
\hline - & $\bullet$ & $\bullet$ & - & - & - & $\bullet$ \\
\hline & & • & & & & \\
\hline & & $\bullet$ & $\bullet$ & & & \\
\hline & & - & - & & & \\
\hline & $\bullet$ & & $\bullet$ & & & \\
\hline & & & & $\bullet$ & & \\
\hline & & • & • & • & • & • \\
\hline
\end{tabular}

BPI-sf, Brief Pain Inventory short form; LOS, length of stay.

Pre-medication will be given 1 hour before surgery, as follows:

- $1 \mathrm{~g}$ paracetamol (acetaminophen) per oral (PO) to all patients.

- $400 \mathrm{mg}$ ibuprofen PO to patients with an ideal body weight (IBW) under $60 \mathrm{~kg} ; 600 \mathrm{mg}$ Ibuprofen PO to patients with IBW over $60 \mathrm{~kg}$; $800 \mathrm{mg}$ ibuprofen PO to patients younger than 65 years and with an IBW over $80 \mathrm{~kg}$. IBW was approximated by calculating BMI 22 from a patient's height. ${ }^{51}$

- $5 \mathrm{mg}$ diazepam PO to all patients.

- Pre-existing long-term medication will be used according to Finnish good practice guidelines. ${ }^{52}$

- $3 \mathrm{~g}$ cefuroxime will be given intravenously to all patients $30-60 \mathrm{~min}$ before surgery or, if allergic to cephalosporins, $4 \times 600 \mathrm{mg}$ clindamycin intravenous will be administered over 24 hours.

Non-tourniquet patients are given $1 \mathrm{~g}$ tranexamic acid intravenously $5-10 \mathrm{~min}$ before the operation, while patients with a tourniquet are given $1 \mathrm{~g}$ tranexamic acid intravenously 5-10 min before releasing the tourniquet. Peripheral oxygen saturation (SpO2), non-invasive blood pressure and ECG monitoring will be used for all patients. Arterial cannula will be placed only if there is a clear need for invasive monitoring of haemodynamics or arterial blood gas analysis. The mean arterial pressure objective is $\geq 65 \mathrm{~mm} \mathrm{Hg}$ or $\geq 70-75 \mathrm{~mm} \mathrm{Hg}$ if there is significant risk of ischaemia. Patients will be warmed with heat mattresses and, after isolation of the sterile area, also with hot-air blankets. Patients are placed in operating position according to routine practice.

The tourniquet cuff will be set even if it is not used, according to randomisation. In the tourniquet group, the surgeon raises the limb, veins are drained using a roll-on cuff and the tourniquet is inflated immediately before the incision. The tourniquet pressure level is set at $250 \mathrm{~mm} \mathrm{Hg}$ ( $\min \geq 100 \mathrm{~mm} \mathrm{Hg}$ over systolic pressure). The maximum tourniquet time is set to 2 hours. The tourniquet is deflated immediately after the wound closure, patch and bandage application. The tourniquet pressure and time are recorded.

Primary medications for minor blood circulation support are 2-3 mg etilefrine or $0.1-0.2 \mathrm{mg}$ phenylephrine intravenous boluses. Moreover, $0.04 \mathrm{mg} / \mathrm{mL}$ noradrenalin (norepinephrine) intravenous is infused in case of continuous hypotension. The maximum limit of systolic pressure is $130 \mathrm{~mm} \mathrm{Hg}$ to minimise intraoperative bleeding. For hypertensive patients, anaesthesia is deepened and 10-20 mg labetalol intravenous and/or 75-150 $\mu \mathrm{g}$ clonidine intravenous are administered if necessary. Blood loss substitution limits (transfusion thresholds) are haemoglobin $<80 \mathrm{~g} / \mathrm{L}$ ( $<90 \mathrm{~g} / \mathrm{L}$ for patients with significant ischaemia risk), thrombocytes $<100 \mathrm{e} 9 / \mathrm{L}$ and international normalised ratio $>1.7$ (ie, Owren thromboplastin time/ prothrombin time $<32 \%$ ). Furthermore, $4 \mathrm{mg}$ ondansetron intravenous is administered to all patients during the closure of the wound. ${ }^{53}$

\section{Protocol for SA, with or without a tourniquet}

A dose of 2.5-5 mg diazepam intravenous and/or 25-50 $\mu \mathrm{g}$ fentanyl intravenous is given on demand before SA. The primary puncture site is between the L 3 and $\mathrm{L} 4$ vertebrae, and the secondary site is between L2 and L3. A Quincke 27 G (BD, Ontario, Canada) needle is used primarily and a Quincke $25 \mathrm{G}$ needle secondarily. SA is set with $15 \mathrm{mg}$ of isobaric bupivacaine (Bicain Spinal $5 \mathrm{mg} / \mathrm{mL}$; Orion, Espoo, Finland). Local anaesthesia of the vein is done using $2 \mathrm{~mL}(10 \mathrm{mg} / \mathrm{mL})$ lidocaine intravenously on demand. Sedation is done with $20 \mathrm{mg} / \mathrm{mL}$ propofol infusion (maximum $4 \mathrm{mg} / \mathrm{kg} / \mathrm{h}$ ) until the patient is sedated but spontaneously breathing, aimed at reaching level $0-2$ on the Richmond Agitation Sedation Scale. ${ }^{54}$ Extra 
oxygen via nasal cannula or venture mask is given in the case of $\mathrm{SpO} 2$ dropping below $94 \%$.

\section{Protocol for GA, with or without a tourniquet}

A dose of $0.2 \mathrm{mg}$ glycopyrronium intravenous is given on demand and local anaesthesia of the vein is done with $2 \mathrm{~mL}(10 \mathrm{mg} / \mathrm{mL})$ lidocaine intravenous. A GE Entropy EasyFit sensor and a GE neuromuscular transmission monitor (both GE Healthcare Finland Oy, Helsinki, Finland) will be applied to all GA patients. Propofol anaesthesia is given with a target-controlled infusion (TCI): TCI Schnider-formula; effect site-target $4 \mu \mathrm{g} / \mathrm{mL}$, adjusted if required to $3-8 \mu \mathrm{g} / \mathrm{mL}$, to achieve an entropy level of 30-50. Remifentanil infusion is given with TCI: TCI Minto-formula; effect site-target $1 \mathrm{ng} / \mathrm{mL}$, adjusted to $3 \mathrm{ng} / \mathrm{mL}$ before the tourniquet and incision, and the infusion is adjusted to $1-8 \mathrm{ng} / \mathrm{mL}$ according to the patient's heart rate and blood pressure. A dose of $0.5 \mathrm{mg}$ / $\mathrm{kg}$ rocuronium is given for intubation, with extra doses of $0.1-0.2 \mathrm{mg} / \mathrm{kg}$ given only if surgically required and avoided for $30 \mathrm{~min}$ before wound closure. The patient is intubated according to routine protocols and ventilated with pressure-controlled ventilation in the volume-guaranteed ventilation mode (PCV-VG mode; Aisys Carestation, GE Healthcare):

- Oxygen/air mixture.

- Tidal volume $6-8 \mathrm{~mL} / \mathrm{kg}$ (for IBW).

- Positive end-expiratory pressure $5-7 \mathrm{cmH}_{2} \mathrm{O}$.

- Inspiration:expiration ratio of 1:1.5-2.

- Target end-tidal oxygen level 30\%-50\%.

- Target end-tidal carbon dioxide level $4.5-5 \mathrm{kPa}$.

Twenty minutes before the end of the surgery, $0.1 \mathrm{mg} /$ $\mathrm{kg}$ oxycodone intravenous (for IBW) is administered and the remifentanil infusion is stopped. The neuromuscular block is reversed with $0.5 \mathrm{mg}$ glycopyrronium and $2.5 \mathrm{mg}$ neostigmine intravenous or, for deep relaxation, $2 \mathrm{mg} / \mathrm{kg}$ sugammadex intravenous.

\section{TKA surgery}

TKA is performed from a ventral incision and medial parapatellar arthrotomy with Triathlon CR/CS/PS total knee system (Stryker, Kalamazoo, Michigan, USA). All patellas are everted and resurfaced to avoid possible postoperative patellar pain as a confounding factor. TKA instrumentation and implantation are performed according to the cemented Triathlon knee system technique. Intramedullary femoral and extramedullary tibial reference guides are used. A femoral guide canal blockade is made with an autologous bone graft or cement. Local infiltration analgesia (LIA $)^{55} 56$ is used for all subjects: $150 \mathrm{~mL}(2 \mathrm{mg} / \mathrm{mL})$ ropivacaine with $5 \mathrm{~mL}(0.1 \mathrm{mg} / \mathrm{mL})$ adrenalin and $1 \mathrm{~mL}$ $(30 \mathrm{mg} / \mathrm{mL})$ ketorolac is injected using a systematic multipuncture technique. The first $60-70 \mathrm{~mL}$ is injected into the posterior capsule and PCL origin before implantation of the prosthesis and the remaining $86-96 \mathrm{~mL}$ is injected after prosthesis implantation into ligament attachments, Hoffa's fat tissue, the joint capsule and all surrounding tissues incised, instrumented or handled. Subsequently,
$50 \mathrm{~mL}(2 \mathrm{mg} / \mathrm{mL})$ ropivacaine is injected into the subcutaneous wound edges. No drains are used. The wound is closed in layers, and the skin is closed using surgical staples. A wound patch and elastic bandage are applied. Blood loss is estimated by the team nurses based on blood in the aspirator, sponges and drapes, and the pulsatile lavage fluid used according to our routine practice. The haemoglobin and haematocrit levels are measured preoperatively and postoperatively (first postoperative morning) according to our clinic's routine practice, independent of the study. Thus, the blood loss can also be calculated using the haemoglobin balance method and Gross equation. ${ }^{57}$

\section{Postoperative observation, care and medication}

Observation and care

All patients undergoing TKA go to the PACU for continuous monitoring of vital signs, pain and PONV. They are transferred to the ward when they meet the following PACU discharge criteria:

- Patient responds to verbal stimuli.

- Patient can raise and hold his or her head up.

- Spinal anaesthesia patient can bend the non-operated knee.

- Breathing is easy.

- $\mathrm{SpO} 2 \geq 94 \%$ (at most $2 \mathrm{~L} / \mathrm{min}$ oxygen support with a nasal oxygen cannula); for pulmonary disease, the patient's saturation must be equal to preoperative levels.

- Mean arterial pressure $\geq 65 \mathrm{~mm} \mathrm{Hg}$.

- Heart rate between 35 and 110 beats/min.

- Pain NRS score $\leq 4$.

- No continuous postoperative nausea and vomiting.

- Bleeding from the wound is minimal.

The anaesthetist will be consulted if problems arise. Postoperative care on the wards is conducted using the fast-track protocol usually followed in our institution (ie, multimodal medication, fast ambulation and rehabilitation).

\section{Analgesics}

On arriving in the PACU, patients receive a PCA pump for 24 hours. The PCA pump is programmed to allow a maximum of four doses of $0.04 \mathrm{mg} / \mathrm{kg}$ for IBW per hour of $2 \mathrm{mg} / \mathrm{mL}$ oxycodone. The lock-up time between doses is $10 \mathrm{~min}$. All patients are given daily $3 \times 1 \mathrm{~g}$ paracetamol $\mathrm{PO}$ and the following doses of ibuprofen based on IBW: $400 \mathrm{mg}$ PO for patients with an IBW under $60 \mathrm{~kg}, 600 \mathrm{mg}$ PO for patients with an IBW over $60 \mathrm{~kg}$, and $800 \mathrm{mg}$ PO for patients younger than 65 years and with an IBW over $80 \mathrm{~kg}$. Patients at high risk of suffering adverse effects from ibuprofen (eg, those with gastrointestinal irritation or receiving long-term anticoagulant/antithrombotic therapy) receive ibuprofen for only 2 days. After PCA, prolonged-release oxycodone $(5 \mathrm{mg}$ for patients with an IBW of under $50 \mathrm{~kg}, 10 \mathrm{mg}$ for patients with an IBW of $50-75 \mathrm{~kg}$ and $15 \mathrm{mg}$ for patients with an IBW above $75 \mathrm{~kg}$ ) is given PO to each patient in the evening of the first 
postoperative day. After PCA, patients receive oxycodone PO on demand $(5 \mathrm{mg}$ for patients with an IBW of under $50 \mathrm{~kg}, 10 \mathrm{mg}$ for an IBW of $50-70 \mathrm{~kg}$ and $15 \mathrm{mg}$ for patients with an IBW above $75 \mathrm{~kg}$ ) or, if unable to digest the tablets due PONV, oxycodone boluses intramuscularly $(4 \mathrm{mg}$ for patients with an IBW under $50 \mathrm{~kg}, 8 \mathrm{mg}$ for patients with an IBW of $50-70 \mathrm{~kg}$ and $12 \mathrm{mg}$ for patients with an IBW above $75 \mathrm{~kg}$ ). In cases of intolerable pain (NRS pain repeatedly $\geq 5$ ), $2 \times 75-300 \mathrm{mg}$ pregabalin $\mathrm{PO}$ is used as a rescue medication based on the anaesthetist's evaluation. Then, if the intolerable pain continues, a femoral block is administered. These patients are reported separately in the statistical analyses.

From the second day after the operation onward, patients receive either a combination of $500 \mathrm{mg}$ paracetamol and $30 \mathrm{mg}$ codeine or one to two tablets of $50 \mathrm{mg}$ tramadol PO one to three times per day.

\section{Medication protocol for nausea}

PONV protocols for 24 hours postoperative, in addition to the $4 \mathrm{mg}$ ondansetron intravenously administered in the OR, and on subsequent days are listed below:

24 hours after operating:

1. $0.5 \mathrm{mg}$ dehydrobenzperidol intravenous for patients with an IBW of $<70 \mathrm{~kg} ; 0.75 \mathrm{mg}$ dehydrobenzperidol intravenous for patients with an IBW of $\geq 70 \mathrm{~kg}$.

2. $4 \mathrm{mg}$ ondansetron intravenous.

3. $0.5 \mathrm{mg}$ dehydrobenzperidol intravenous for patients with an IBW of $<70 \mathrm{~kg} ; 0.75 \mathrm{mg}$ dehydrobenzperidol intravenous for patients with an IBW of $\geq 70 \mathrm{~kg}$.

4. $0.1 \mathrm{mg} / \mathrm{kg}$ dexamethasone (IBW) intravenous diluted in $100 \mathrm{~mL} \mathrm{NaCl} 0.9 \%$.

5. $6.25 \mathrm{mg}$ promethazine hydrochloride intravenous.

6. $0.5 \mathrm{mg}$ dehydrobenzperidol intravenous for patients with an IBW of $<70 \mathrm{~kg} ; 0.75 \mathrm{mg}$ dehydrobenzperidol intravenous for patients with an IBW of $\geq 70 \mathrm{~kg}$.

7. $6.25 \mathrm{mg}$ promethazine hydrochloride intravenous.

For subsequent days:

1. $4 \mathrm{mg}$ ondansetron intravenous.

2. $0.5 \mathrm{mg}$ dehydrobenzperidol intravenous for patients with an IBW of $<70 \mathrm{~kg} ; 0.75 \mathrm{mg}$ dehydrobenzperidol intravenous for patients with an IBW of $\geq 70 \mathrm{~kg}$.

3. $4 \mathrm{mg}$ ondansetron intravenous.

4. $0.5 \mathrm{mg}$ dehydrobenzperidol intravenous for patients with an IBW of $<70 \mathrm{~kg} ; 0.75 \mathrm{mg}$ dehydrobenzperidol intravenous for patients with an IBW of $\geq 70 \mathrm{~kg}$.

5. $0.5 \mathrm{mg}$ dehydrobenzperidol intravenous for patients with an IBW of $<70 \mathrm{~kg} ; 0.75 \mathrm{mg}$ dehydrobenzperidol intravenous for patients with an IBW of $\geq 70 \mathrm{~kg}$.

\section{Thromboprophylaxis}

Thromboprophylaxis is carried out once daily with $40 \mathrm{mg} / \mathrm{mL}$ enoxaparin administered subcutaneously. Prophylaxis begins 6 hours after surgery and is continued for 14 days postoperatively. Patients with presurgical anticoagulant pharmacotherapy, or thromboembolic or haemorrhagic diseases are treated according to specific treatment protocols.
Other medication

One dose of macrogol (12g) PO daily and, if required, $40 \mathrm{mg}$ omeprazole is given daily. Patients' long-term medication is continued according to the anaesthetists' instructions based on Finnish good practice guidelines.

\section{Discharge}

The patients are discharged from the hospital when they meet the hospital's discharge criteria. At hospital discharge, the patients are instructed to contact the clinic when necessary. The patients are invited for 3-month and 12-month postoperative follow-up visits, where the orthopaedic surgeon performs a clinical examination and the patient returns the study questionnaires (OKS, 15D, BPI-sf; see table 1).

\section{OUTCOMES, MEASUREMENTS AND DATA COLLECTION Primary outcome measures}

- Acute postoperative pain measured by PCA oxycodone consumption during the first 24 hours.

\section{Secondary outcome measures}

- Patient-reported pain, as measured by the pain NRS 24 hours after surgery, and any need for rescue medication.

- Number of PONV medication doses; patient-reported PONV, as measured by the nausea NRS; and patient-reported periods of vomiting 24 hours after surgery.

- Postsurgical LOS (days).

- Operation, OR and PACU times.

- Blood loss during surgery, need for blood transfusion, continuous intra-arterial blood pressure monitoring, haemodynamics medication, ventilation support or urine catheter.

- Knee function, as measured by ROM and OKS preoperatively and 3 and 12 months postoperatively.

- Health-related quality of life (15D questionnaire) measured preoperatively and 3 and 12 months postoperatively.

- Recorded complications and 3-month and 12-month readmissions.

- Chronic pain incidence using the BPI-sf preoperatively and 3 and 12 months postoperatively.

- LOS, complications and mortality, readmissions, need for intensive care, surgical outcome (OKS, ROM), quality of life (15D questionnaire), acute or prolonged pain (BPI-sf) in relation to body composition.

- Predictive value of the chronic pain risk index by factors described by Althaus $e t a l .{ }^{43}$

Validated Finnish and Swedish translations of the OKS, $15 \mathrm{D}$ and BPI-sf questionnaires are used with permission from the copyright holders.

\section{STUDY SCHEDULE}

Patient enrolment began on the third of October 2016. It is estimated that it will take approximately 2 years to enrol 
400 patients for the trial. Patients will visit the outpatient clinic at 3 and 12 months postoperatively. The study is estimated to end in December 2019, with results reporting between 2019 and 2022. For a schematic timeline, see table 1 .

\section{SAMPLE SIZE CALCULATIONS AND POWER}

The sample sizes were calculated using two-tailed tests with an alpha level of $0.05 \%$ and $80 \%$ power. The sample sizes were first evaluated using parametric methods and then inflated by $16 \%$ to accommodate possible non-parametric analyses.

For 24hours PCA opioid consumption (GA vs SA, two groups): Harsten et $a l^{23}$ published 24 hours median PCA morphine equivalent consumption in TKA (with LIA) as $19 \mathrm{mg}(11-28 \mathrm{mg}$ ) for SA and $54 \mathrm{mg}(37-78 \mathrm{mg}$ ) for GA, consistent with the results of other studies. ${ }^{58-60}$ We consider a $20 \%$ difference in PCA opioid consumption as clinically significant. The minimum sample size for non-parametric between-group comparisons is 104 patients per group.

For knee function as measured by OKS: Beard et $a l^{22}$ published the mean OKS result prior to TKA as 18.47 (SD 7.95), with the minimal important change (MIC) for preoperative and postoperative tests for the same patient being 6.5 and the MIC between two independent groups being 4.84 . The minimum sample size for non-parametric between-group comparisons is 51 per group.

For the $15 \mathrm{D}$ questionnaire: Räsänen et $a l^{36}$ published the mean 15D score before TKA as 0.81 (SD 0.093). With the MIC of $\geq 0.03,{ }^{3861}$ the minimum sample size for non-parametric between-group comparisons is 177 per group.

For blood loss with or without a tourniquet: Harsten et $a t^{26}$ published median blood loss with a tourniquet as $56 \mathrm{~mL}$ (IQR 25-118mL) and without a tourniquet as $182 \mathrm{~mL}$ (IQR $89-243 \mathrm{~mL}$ ). However, in our experience, blood loss with a tourniquet is $0-100 \mathrm{~mL}$, and we consider only an over-100 mL difference as having any clinical significance. With an estimated SD of $200 \mathrm{~mL}$, the minimum sample size for non-parametric between-group comparisons is 75 per group.

For LOS: Harsten et $a t^{23}$ reported LOS after TKA as 46 hours for GA and 52 hours for SA. In our hospital, the average LOS is estimated to be 2-3 days (48-72 hours). We consider a change of 1 day to be clinically significant. With an estimated SD of 2 days, the minimum sample size for non-parametric between-group comparison is 75 per group.

For OR time: Based on a small sample extracted from our Centricity Opera Operating Theatre Management Solution, our average OR time is estimated as $161.5 \mathrm{~min}$ (SD $14.2 \mathrm{~min}$ ). We consider a $5 \%$ change in OR time as being clinically significant. The minimum sample size for non-parametric between-group comparison is 60 per group.
For pain as measured by BPI-sf: Høvik $e t a l^{62}$ described the mean BPI-sf 'average pain' score in patients undergoing TKA as 5.5 (SD 2.2). MICs for BPI-sf scores in non-cancer pain were not found in the literature; for cancer pain, they are $0.4-1.3$ for severity scores and $0.5-1.7$ for interference scores. ${ }^{63}$ With an estimated MIC 1.0, the minimum sample size for non-parametric between-group comparison is 90 per group.

For correlations, examples such as correlating patient body fat percentage (as measured by bioelectrical impedance) with LOS and Althaus risk index with BPI-sf pain scores, we consider Pearson $r \leq 0.3$ as indicating no correlation between variables, $r \geq 0.5$ as indicating a possible correlation and $r \geq 0.7$ as indicating a likely correlation. To detect a possible correlation $(r=0.3)$ between variables, the minimum sample is 29 patients, and to detect a likely correlation, the minimum sample is 84 patients.

\section{DATA MANAGEMENT AND STATISTICAL ANALYSIS}

\section{Data management and confidentiality}

The study data are stored in the Helsinki University Hospital patient data and research registers in accordance with the Finnish Personal Data $\mathrm{Act}^{64}$ and the EU General Data Protection Regulation (www.eugdpr.org). The registration descriptions are enclosed with the Ethics Committee statement. Access to the data is only available to personnel participating in the study, and no information is provided to non-examiners. For computer analysis, all personal data are encoded so that patients are unidentifiable when processing or reporting the results. Patient consent forms, the randomisation data of the patient groups, the research results and other papers related to the research are stored in a locked cabinet at the Peijas Hospital Surgery Department. Electronic documents are password-protected automatically and are stored on the back-up Helsinki University Hospital network hard disk. The Finnish Medicines Agency Fimea has the right to inspect the research site and the research and patient documentation. The information on patients who have cancelled their participation of the study is dealt with in accordance with the Finnish Act on Medical Research (488/99, 6 a §) and the EU General Data Protection Regulation (www.eugdpr.org). The number of patients who drop out will be reported. The papers related to the research are disposed of in the same way as the protected papers of other patients. The files associated with the research will be destroyed by removing them from the network hard disk, and the removal will be ensured through Helsinki University Hospital Data Management.

\section{Statistical analysis}

Data will be analysed with statistics software (latest version of SPSS; IBM). The main interest will be comparing the difference in outcomes between the GA and SA groups. The comparisons between the GA and SA groups will be adjusted to address tourniquet use. In the comparisons between patients with or without tourniquets, an 
adjustment for the type of anaesthesia regimen will be used. Additionally, comparisons between the four study groups will be made. The modifying effect of gender, age, ASA physical status class, BMI, primary or secondary osteoarthritis, previous partial meniscectomy or debridement, tobacco use, alcohol use, depression and diabetes on the differences between the SA and GA groups will be analysed using the modifier by group interaction effects in the models. Interaction analyses are exploratory in nature.

For statistical analyses, a professional statistician, Tero Vahlberg, is being consulted.

\section{MONITORING \\ Patient safety}

The Finnish Medical Research Law (488/99, 10 e $\S$ and $10 \mathrm{f} \S)$ and the Patient Safety Plan of the Hospital District of Helsinki and Uusimaa are observed in this study. Possible unexpected adverse effects from medication are reported to the Finnish Medicines Agency Fimea. As with any other patient in the hospital, any patient complications are treated based on best practices. Doctors comprising surgeons, anaesthetists and internists are at the hospital continuously. The patients are insured by Helsinki University Hospital patient insurance, according to Finnish law.

\section{ETHICS AND DISSEMINATION}

This study protocol is in accordance with the most recent version of the World Medical Association Declaration of Helsinki.

\section{Consent}

A patient information sheet is offered to each participant in his or her native language. Patients are informed about both anaesthesia methods and their risks, surgical and other procedures relating to this study, and the study's objectives when they are recruited. All questions regarding the study are answered by the recruiting anaesthetist. The patient is given time to consider if they wish to participate. The patient is informed that he or she can cancel or pause participation in the study for any reason at any time. The withdrawal or suspension of participation does not affect the medical or other treatment of the patient. Participating patients do not incur any costs and no compensation will be paid to patients or any other person involved in the study.

\section{Author affiliations}

${ }^{1}$ Peijas Hospital, Department of Orthopaedics and Traumatology, Arthroplasty Centre, University of Helsinki and Helsinki University Hospital, Vantaa, Finland

${ }^{2}$ Peijas Hospital, Department of Anaesthesiology, Intensive Care and Pain Medicine, University of Helsinki and Helsinki University Hospital, Vantaa, Finland

${ }^{3}$ Department of Anaesthesiology, Intensive Care and Pain Medicine, University of Helsinki and Helsinki University Hospital, Helsinki, Finland

Acknowledgements The authors would like to thank adjunct professor Eero Pesonen and adjunct professor Tatu Mäkinen for their kind advice related to the study design, Dr Eliisa Uljas for randomising the patients, and research nurse Arja Mäkelä for controlling patient data deposits and her constant support during this project.

Contributors AV, NKAS, MTR and RP are responsible for the original study planning. KO, AV and NKAS applied for this study's funding. NKAS, RP and MTR trained the hospital personnel. RP, NKAS, PK and ER are responsible for patient recruitment; RP, NKAS and PK for 24-hour evaluation of the patients; and MTR for the 3-month and 12-month postoperative evaluations. $\mathrm{KJ}$ is responsible for controlling patient data deposits. MTR, RP and NKAS will check the data input. ER, $\mathrm{RL}, \mathrm{RM}$ and TH are experts in outcome-prediction models, intensive care and severe complications, and orthopaedic research. All authors will participate in analysing and reporting the results. For statistical analyses, a professional statistician is being consulted. MTR, AV and NKAS conceived the study. All authors contributed to refining the study protocol and approving the final manuscript.

Funding This study has received a Helsinki University Hospital grant (Y102011095) and a Helsinki University Hospital Finnish Government science grant (TYH2017239). This study received no other grants from any other funding agency in the public, commercial or non-profit sectors.

Competing interests None declared.

Patient consent for publication Obtained.

Ethics approval Ethics Committee of the Hospital District of Helsinki and Uusimaa, Finnish Medicines Agency Fimea.

Provenance and peer review Not commissioned; externally peer reviewed.

Author note The Triathlon Knee System, instrumentation, equipment and medication have been selected based on pre-existing Helsinki University supply contracts independent of the study.

Open access This is an open access article distributed in accordance with the Creative Commons Attribution Non Commercial (CC BY-NC 4.0) license, which permits others to distribute, remix, adapt, build upon this work non-commercially, and license their derivative works on different terms, provided the original work is properly cited, appropriate credit is given, any changes made indicated, and the use is non-commercial. See: http://creativecommons.org/licenses/by-nc/4.0/.

\section{REFERENCES}

1. Jenkins PJ, Clement ND, Hamilton DF, et al. Predicting the costeffectiveness of total hip and knee replacement: a health economic analysis. Bone Joint J 2013;95-B:115-21.

2. Kurtz SM, Ong KL, Lau E, et al. Impact of the economic downturn on total joint replacement demand in the United States: updated projections to 2021. J Bone Joint Surg Am 2014;96:624-30.

3. Patel A, Pavlou G, Mújica-Mota RE, et al. The epidemiology of revision total knee and hip arthroplasty in England and Wales: a comparative analysis with projections for the United States. A study using the national joint registry dataset. Bone Joint $J$ 2015;97B:1076-81.

4. Kehlet $\mathrm{H}$, Thienpont E. Fast-track knee arthroplasty-status and future challenges. Knee 2013;20:S29-33.

5. Otero JE, Gholson JJ, Pugely AJ, et al. Length of hospitalization after joint arthroplasty: does early discharge affect complications and readmission rates? J Arthroplasty 2016;31:2714-25.

6. Sutton JC, Antoniou J, Epure LM, et al. Hospital discharge within 2 days following total hip or knee arthroplasty does not increase major-complication and readmission rates. J Bone Joint Surg Am 2016;98:1419-28.

7. Kehlet H. Fast-track hip and knee arthroplasty. Lancet 2013;381:1600-2.

8. Kehlet H, Dahl JB. Anaesthesia, surgery, and challenges in postoperative recovery. Lancet 2003;362:1921-8.

9. Beswick AD, Wylde V, Gooberman-Hill R, et al. What proportion of patients report long-term pain after total hip or knee replacement for osteoarthritis? A systematic review of prospective studies in unselected patients. BMJ Open 2012;2:e000435.

10. Gunaratne R, Pratt DN, Banda J, et al. Patient dissatisfaction following total knee arthroplasty: a systematic review of the literature. J Arthroplasty 2017;32:3854-60.

11. Puolakka PA, Rorarius MG, Roviola $M$, et al. Persistent pain following knee arthroplasty. Eur J Anaesthesiol 2010;27:455-60.

12. Scott CE, Howie CR, MacDonald D, et al. Predicting dissatisfaction following total knee replacement: a prospective study of 1217 patients. J Bone Joint Surg Br 2010;92:1253-8. 
13. Goesling J, Moser SE, Zaidi B, et al. Trends and predictors of opioid use after total knee and total hip arthroplasty. Pain 2016;157:1259-65.

14. Saku SA, Madanat R, Mäkinen TJ. Reasons and risk factors for ninety day re-admission following primary total knee arthroplasty in a high-volume centre. Int Orthop 2018;42:95-9.

15. Sadoghi P, Liebensteiner M, Agreiter M, et al. Revision surgery after total joint arthroplasty: a complication-based analysis using worldwide arthroplasty registers. J Arthroplasty 2013;28:1329-32.

16. Gulur P, Nishimori M, Ballantyne JC. Regional anaesthesia versus general anaesthesia, morbidity and mortality. Best Pract Res Clin Anaesthesiol 2006;20:249-63.

17. Memtsoudis SG, Sun X, Chiu YL, et al. Utilization of critical care services among patients undergoing total hip and knee arthroplasty: epidemiology and risk factors. Anesthesiology 2012;117:107-16.

18. Memtsoudis SG, Sun X, Chiu YL, et al. Perioperative comparative effectiveness of anesthetic technique in orthopedic patients. Anesthesiology 2013;118:1046-58.

19. Perlas A, Chan VW, Beattie S. Anesthesia technique and mortality after total hip or knee arthroplasty: a retrospective, propensity scorematched cohort study. Anesthesiology 2016;125:724-31.

20. Rodgers A, Walker N, Schug S, et al. Reduction of postoperative mortality and morbidity with epidural or spinal anaesthesia: results from overview of randomised trials. BMJ 2000;321:1493.

21. Moen V, Dahlgren N, Irestedt L. Severe neurological complications after central neuraxial blockades in Sweden 1990-1999. Anesthesiology 2004;101:950-9.

22. Johnson RL, Kopp SL, Burkle CM, et al. Neuraxial vs general anaesthesia for total hip and total knee arthroplasty: a systematic review of comparative-effectiveness research. $B r J$ Anaesth 2016;116:163-76.

23. Harsten $\mathrm{A}$, Kehlet $\mathrm{H}$, Toksvig-Larsen $\mathrm{S}$. Recovery after total intravenous general anaesthesia or spinal anaesthesia for total knee arthroplasty: a randomized trial. Br J Anaesth 2013;111:391-9.

24. Dennis DA, Kittelson AJ, Yang CC, et al. Does tourniquet use in TKA affect recovery of lower extremity strength and function? A randomized trial. Clin Orthop Relat Res 2016;474:69-77.

25. Ejaz A, Laursen AC, Jakobsen T, et al. Absence of a tourniquet does not affect fixation of cemented TKA: a randomized RSA study of 70 patients. J Arthroplasty 2015;30:2128-32.

26. Harsten A, Bandholm T, Kehlet $\mathrm{H}$, et al. Tourniquet versus no tourniquet on knee-extension strength early after fast-track total knee arthroplasty; a randomized controlled trial. Knee 2015;22:126-30.

27. Schnettler T, Papillon N, Rees H. Use of a tourniquet in total knee arthroplasty causes a paradoxical increase in total blood loss. $J$ Bone Joint Surg Am 2017;99:1331-6.

28. Smith TO, Hing CB. Is a tourniquet beneficial in total knee replacement surgery? A meta-analysis and systematic review. Knee 2010;17:141-7.

29. Stetzelberger V, Obertacke U, Jawhar A. Tourniquet application during TKA did not affect the accuracy of implant positioning: a randomized clinical trial. Knee Surg Sports Traumatol Arthrosc 2018;26:1728-36.

30. Fischer HB, Simanski CJ, Sharp C, et al. A procedure-specific systematic review and consensus recommendations for postoperative analgesia following total knee arthroplasty. Anaesthesia 2008;63:1105-23.

31. Järvistö A. Polven tekonivelleikkauksen tulosta arvioivan nivelspesifisen tulosmittarin (Oxford Knee Score) kääntäminen suomen kielelle [Master's theses (medicine)]. Finland: Tampere University, 2015.

32. Beard DJ, Harris K, Dawson J, et al. Meaningful changes for the Oxford hip and knee scores after joint replacement surgery. $J$ Clin Epidemiol 2015;68:73-9.

33. Dawson J, Fitzpatrick R, Murray D, et al. Questionnaire on the perceptions of patients about total knee replacement. J Bone Joint Surg Br 1998;80:63-9.

34. Murray DW, Fitzpatrick R, Rogers K, et al. The use of the Oxford hip and knee scores. J Bone Joint Surg Br 2007;89:1010-4.

35. Sintonen $\mathrm{H}$. The $15 \mathrm{D}$ instrument of health-related quality of life: properties and applications. Ann Med 2001;33:328-36.

36. Räsänen $\mathrm{P}$, Paavolainen $\mathrm{P}$, Sintonen $\mathrm{H}$, et al. Effectiveness of hip or knee replacement surgery in terms of quality-adjusted life years and costs. Acta Orthop 2007;78:108-15.

37. Sintonen $\mathrm{H}$. The 15D-measure of health-related quality of life. II. Feasibility, reliability and validity of its valuation system. Melbourne: National Centre for Health Program Evaluation, 1995.

38. Sintonen $\mathrm{H}$, Richardson J. The 15-D measure of health related quality of life: reliability, validity and sensitivity of its health state descriptive system. Melbourne: National Centre for Health Program Evaluation Melbourne, 1994.
39. Cleeland CS, Gonin R, Hatfield AK, et al. Pain and its treatment in outpatients with metastatic cancer. N Engl J Med 1994;330:592-6.

40. Ledford CK, Ruberte Thiele RA, Appleton JS, et al. Percent body fat more associated with perioperative risks after total joint arthroplasty than body mass index. J Arthroplasty 2014;29:150-4.

41. Pietiläinen $\mathrm{KH}$, Kaye S, Karmi A, et al. Agreement of bioelectrical impedance with dual-energy $\mathrm{X}$-ray absorptiometry and MRI to estimate changes in body fat, skeletal muscle and visceral fat during a 12-month weight loss intervention. Br J Nutr 2013;109:1910-6.

42. Stolzman S, Hoeger Bement M. Lean mass predicts conditioned pain modulation in adolescents across weight status. Eur J Pain 2016;20:967-76.

43. Althaus A, Hinrichs-Rocker A, Chapman R, et al. Development of a risk index for the prediction of chronic post-surgical pain. Eur $J$ Pain 2012;16:901-10.

44. Chan AW, Tetzlaff JM, Altman DG, et al. SPIRIT 2013: new guidance for content of clinical trial protocols. Lancet 2013;381:91-2.

45. Schulz KF, Altman DG, Moher D. CONSORT 2010 statement: updated guidelines for reporting parallel group randomised trials. Int J Surg 2011;9:672-7.

46. Kellgren JH, Lawrence JS. Radiological assessment of osteoarthrosis. Ann Rheum Dis 1957;16:494-502.

47. Anesthesiologists ASo. Asa physical status classification system: American Society of Anesthesiologists. 2014 http://www.asahq.org/ resources/clinical-information/asa-physical-status-classificationsystem\# (accessed 6 Jul 2018).

48. Stinson JN, Kavanagh T, Yamada J, et al. Systematic review of the psychometric properties, interpretability and feasibility of self-report pain intensity measures for use in clinical trials in children and adolescents. Pain 2006;125:143-57.

49. von Baeyer CL. Numerical rating scale for self-report of pain intensity in children and adolescents: recent progress and further questions. Eur J Pain 2009;13:1005-7.

50. Lunn TH, Kristensen BB, Andersen L $\varnothing$, et al. Effect of high-dose preoperative methylprednisolone on pain and recovery after total knee arthroplasty: a randomized, placebo-controlled trial. Br J Anaesth 2011:106:230-8.

51. Lemmens HJ, Brodsky JB, Bernstein DP. Estimating ideal body weight-a new formula. Obes Surg 2005;15:1082-3

52. Käypä hoito. Preoperative evaluation: current care guideline. Duodecim. 2014 http://www.kaypahoito.fi/web/kh/suositukset/ suositus?id=kht00086\&suositusid=hoi50066 (accessed 6 Oct 2018).

53. Gan TJ, Diemunsch P, Habib AS, et al. Consensus guidelines for the management of postoperative nausea and vomiting. Anesth Analg 2014:118:85-113.

54. Ely EW, Truman B, Shintani A, et al. Monitoring sedation status over time in ICU patients: reliability and validity of the Richmond AgitationSedation Scale (RASS). JAMA 2003;289:2983-91.

55. Kerr DR, Kohan L. Local infiltration analgesia: a technique for the control of acute postoperative pain following knee and hip surgery: a case study of 325 patients. Acta Orthop 2008;79:174-83.

56. Kehlet $\mathrm{H}$, Andersen $\mathrm{L} \varnothing$. Local infiltration analgesia in joint replacement: the evidence and recommendations for clinical practice. Acta Anaesthesiol Scand 2011;55:778-84.

57. Gao FQ, Li ZJ, Zhang K, et al. Four methods for calculating bloodloss after total knee arthroplasty. Chin Med J 2015;128:2856-60.

58. Carli F, Clemente A, Asenjo JF, et al. Analgesia and functional outcome after total knee arthroplasty: periarticular infiltration vs continuous femoral nerve block. Br J Anaesth 2010;105:185-95.

59. Widmer BJ, Scholes CJ, Pattullo GG, et al. Is femoral nerve block necessary during total knee arthroplasty?: a randomized controlled trial. J Arthroplasty 2012;27:1800-5.

60. Chan EY, Fransen M, Parker DA, et al. Femoral nerve blocks for acute postoperative pain after knee replacement surgery. Cochrane Database Syst Rev 2014;5:Cd009941.

61. Alanne S, Roine RP, Räsänen $P$, et al. Estimating the minimum important change in the 15D scores. Qual Life Res 2015;24:599-606.

62. Høvik LH, Winther SB, Foss OA, et al. Preoperative pain catastrophizing and postoperative pain after total knee arthroplasty: a prospective cohort study with one year follow-up. BMC Musculoskelet Disord 2016;17:214

63. Raman S, Ding K, Chow E, et al. Minimal clinically important differences in the EORTC QLQ-C30 and brief pain inventory in patients undergoing re-irradiation for painful bone metastases. Qual Life Res 2018;27:1089-98.

64. Finlex Data Bank. Finnish Personal Data Act 523/1999: Ministry of Justice. $2000 \mathrm{https}: / /$ www.finlex.fi/en/laki/kaannokset/1999/ en19990523? search\%5Btype\%5D=pika\&search\%5Bpika\%5D= personal\%20data\%20act (accessed 6 Oct 2018). 